Historic, archived document

Do not assume content reflects current scientific knowledge, policies, or practices. 




\title{
Zinc Deficiency of Field and Vegetable Crops in the West
}

\author{
By Frank G. Viets, Jr., Soil and Water Conservation Research Division, \\ Agricultural Research Service
}

All plants need zinc to develop and fruit normally. The quantity of zinc they demand is very small. A good yield of a field or vegetable crop contains from one-tenth to one-quarter pound of zinc per acre. This means that the zinc needs of such a crop are met by a quantity amounting to only one-hundredth of the same crop's requirement of phosphorus (as $\mathrm{P}_{2} \mathrm{O}_{5}$ ) and only one-thousandth of its requirement of nitrogen. Even so, too little zinc is available in some agricultural soils.

Zinc deficiency was identified in the midthirties as causing failure of fruit and nut trees to grow and produce normally in many irrigated areas of the West. More recently, it has been recognized on field and vegetable crops in both irrigated and dryland areas of the West.

\section{The Sensitive Crops}

Some crop plants show striking symptoms of zinc deficiency on land where other crop plants show none. The crops most frequently stunted and reduced in yield by shortage of available zinc are corn, beans, castorbeans, sorghums, cotton, onions, tomatoes, hops, potatoes, and flax. Crops that rarely show any symptoms of such shortage are small grains, alfalfa, clovers, mint, and grasses. Sugar beets and some other crops are highly sensitive to zinc deficiency in some areas but only moderately sensitive elsewhere.
Crops sensitive to zinc deficiency often show more acute symptoms of it when grown after sugar beets than they do when preceded by another crop. Cold, wet spring weather frequently intensifies their reaction.

\section{The Deficient Soils}

Zinc deficiency is more common where surface soil has been partly or entirely removed by erosion or by leveling of land for irrigation. However, leveling does not always cause zinc deficiency, and undisturbed soils can be deficient in zinc. The deficiency is frequent on old corral sites. Corn has shown it on nonirrigated land in eastern South Dakota and Nebraska, but has not been reported to do so in other nonirrigated areas of the West.

Zinc deficiency can occur in soils of all textures, from sand to clay. In Nebraska, it is more frequent in sandy soils. The deficient soils are more likely to be alkaline (that is, to have a $\mathrm{pH}$ of at least 7) than to be acid, and are likely to contain lime.

A soil can contain a normal quantity of zinc and still be deficient in zinc available to plants.

The deficiency may occur in spots in a field or throughout a field.

\section{Symptoms}

In general, the stems and leaves of zinc-deficient plants fail to develop to normal size, and some of the tissues 


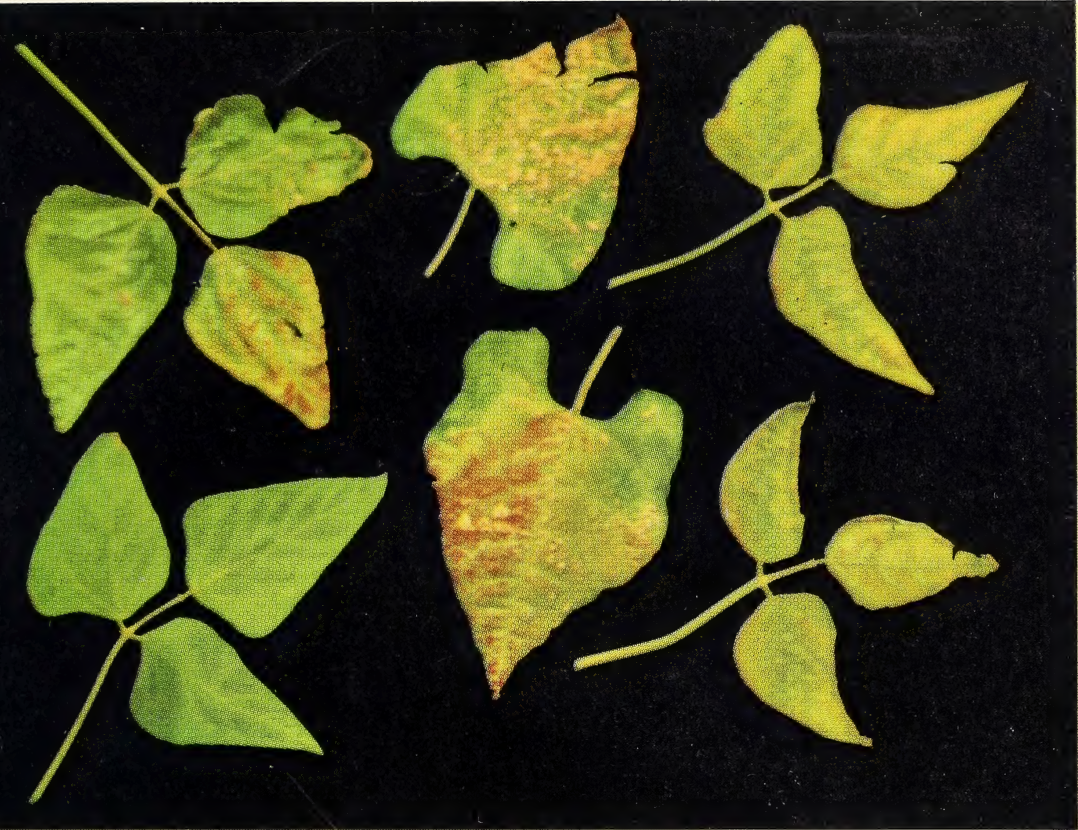

SN-339

Lima bean (Fordhook) leaves affected by zinc deficiency, in contrast with one that is normal. The deficiency has caused yellowing between veins, rusty-brown blotches, and, in the trifoliolate leaves, some stunting and a leathery texture.

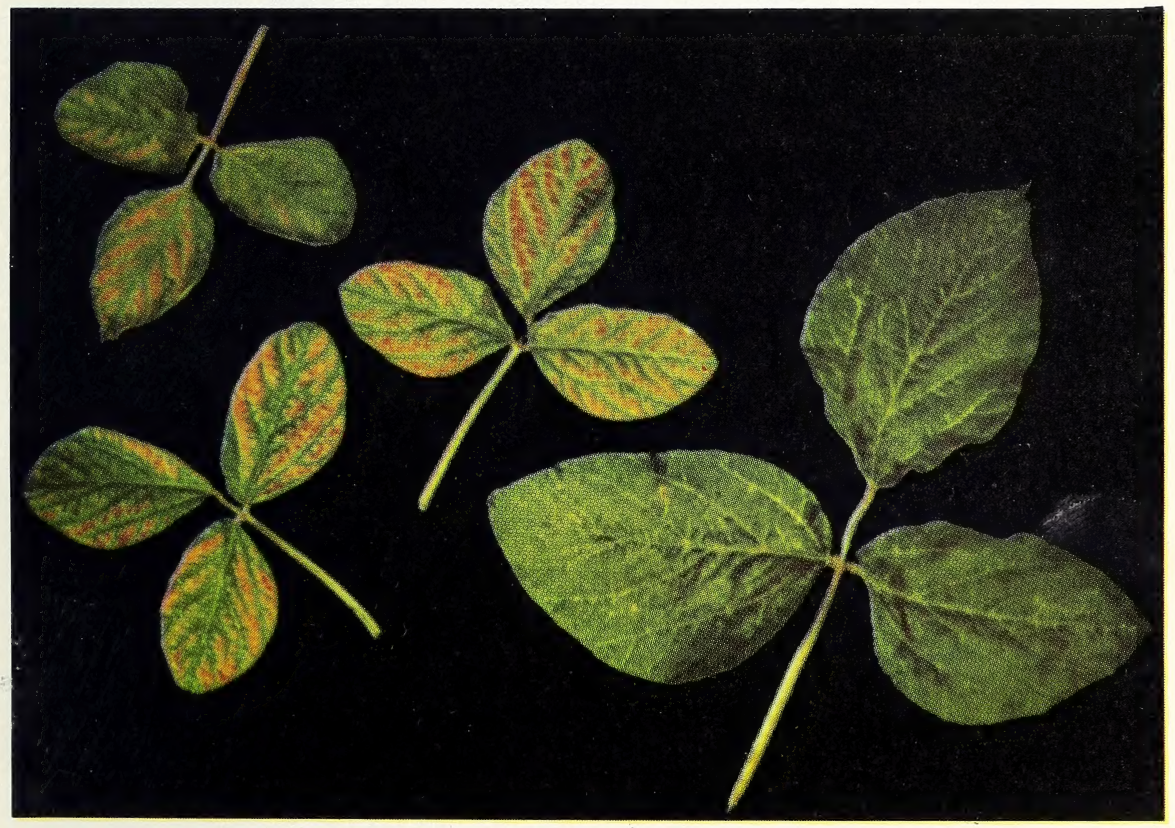

$\mathrm{SN}-340$

Zinc deficiency has stunted and yellowed the three soybean leaves at the left. At the right, a normal soybean leaf in the same stage of growth. 


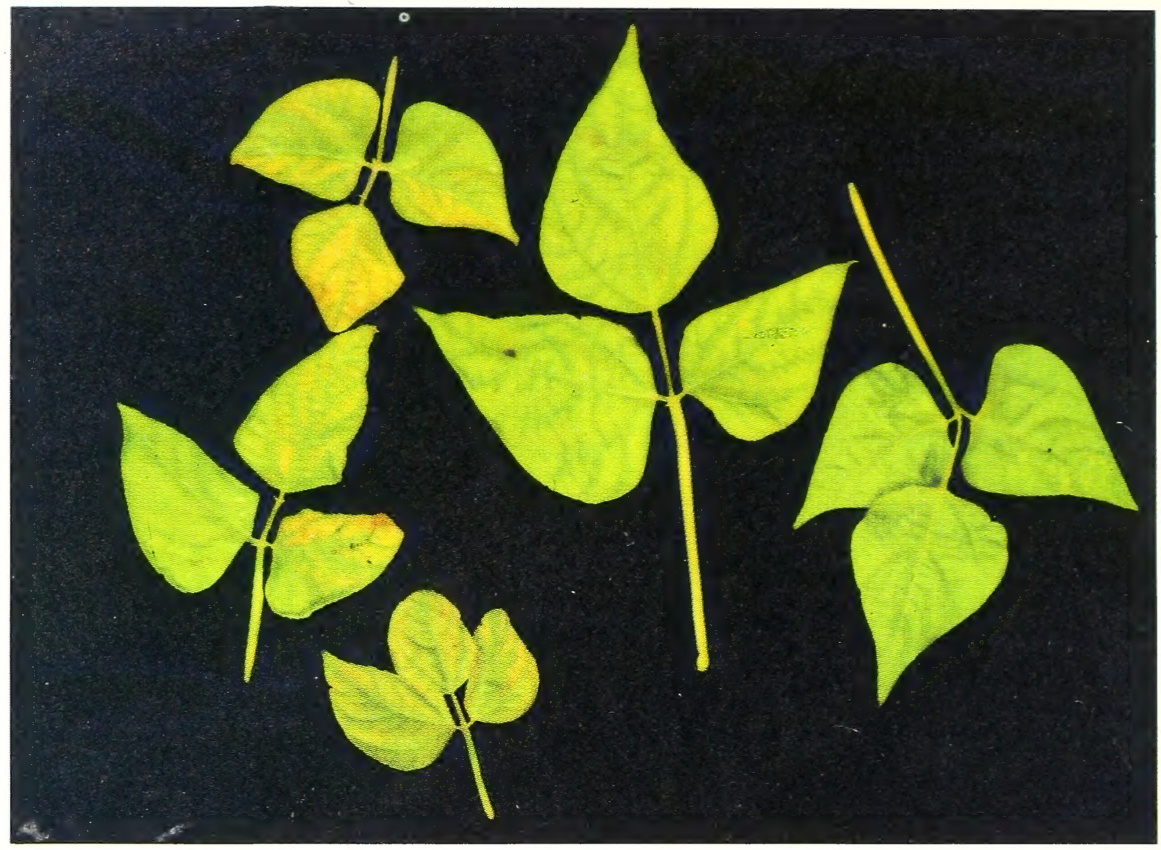

$\mathrm{SN}-341$

Zinc-deficiency symptoms on Red Mexican (U.I. 34) field beans. The yellowing and deformity shown by the three old leaves at the left appear in milder form in the younger leaf at the center. At the right, a normal leaf. (Iron deficiency, also, produces yellowing between the veins of Red Mexican field bean leaves, but it affects the new leaves worse than the old and does not deform the leaves.)

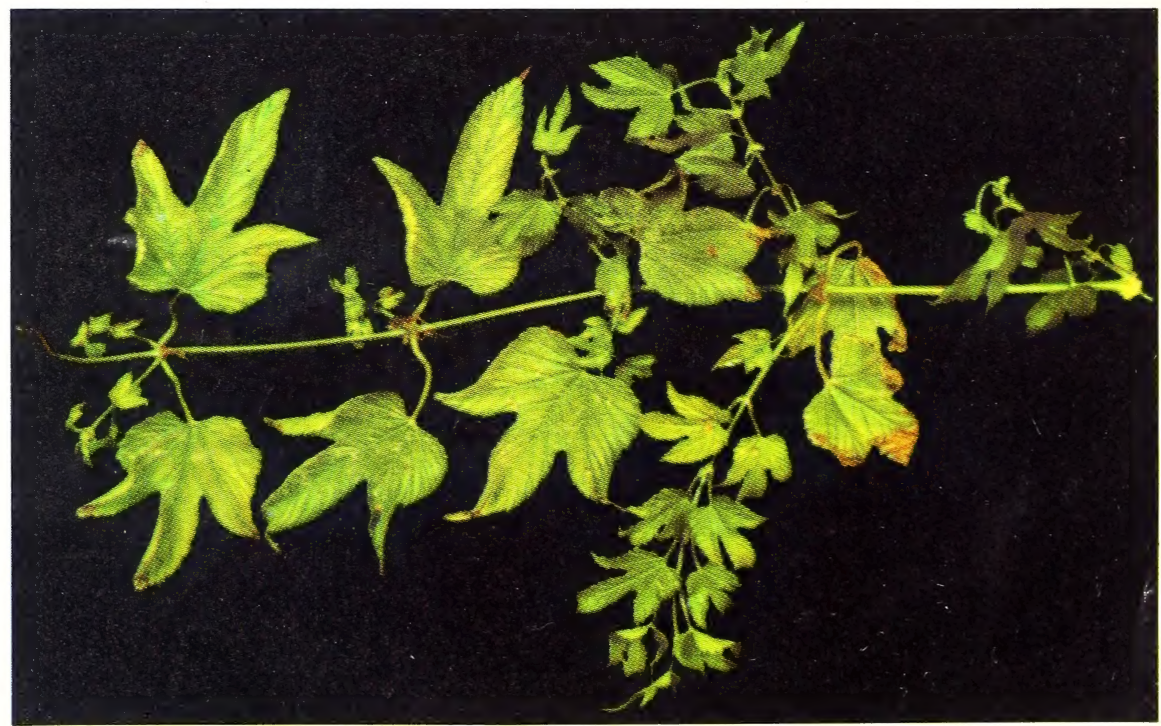

$\mathrm{SN}-342$

Sidearms of this hop branch show effects of zinc deficiency in their greatly shortened internodes and greatly reduced leaf size. The yellowing between veins of leaves on the branch is another effect of this deficiency. 
between the leaf veins contain so little chlorophyll that they turn yellow. This yellowing, technically called chlorosis, is usually worst on the lowest leaves of the plant. The yellowed leaf tissues may turn brown or gray and die prematurely. A zinc-deficient area in a bean field will have a yellowish-brown color when viewed from a distance.

Varieties of some crop plants differ in their ways of reacting to zinc shortage. For example, Russet Burbank, alone among all potato varieties grown commercially in the West, shows a conspicuous stunting of leaves of the terminal growth and does not, like other potatoes, show yellowing of leaf tissues and stunting of lower leaves. Varieties of field beans differ considerably in their reactions.

Symptoms are often more common and more severe at earlier than at later stages of growth. A moderate zinc deficiency, even though it delays maturing of corn or bean plants and limits their yields, may cause no symptoms on new growth of the plants as the root systems develop.

Symptoms of zinc deficiency resemble those of iron, manganese, or magnesium deficiency. This deficiency can occur together with any one or two of the others named, or with all of them.

\section{Diagnosis}

Make sure you diagnose any plant abnormality correctly before you attempt to control it. The symptoms pictured in this leaflet are a good guide to diagnosing zinc deficiency, but they are not entirely reliable. Laboratory tests for determining zinc content of soil are not yet suitable for routine use, and no quick tissue tests can be recommended yet for field use.

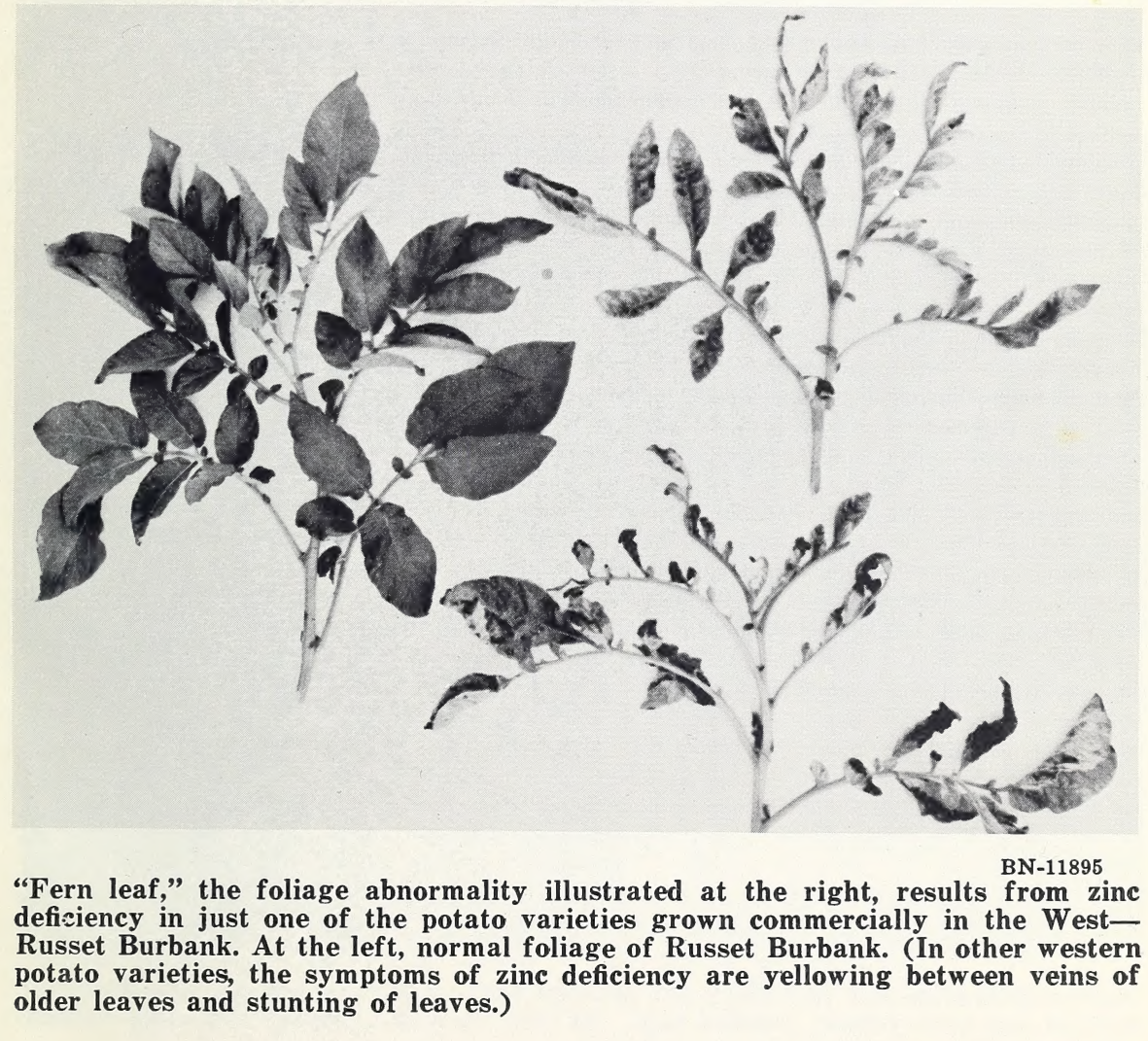




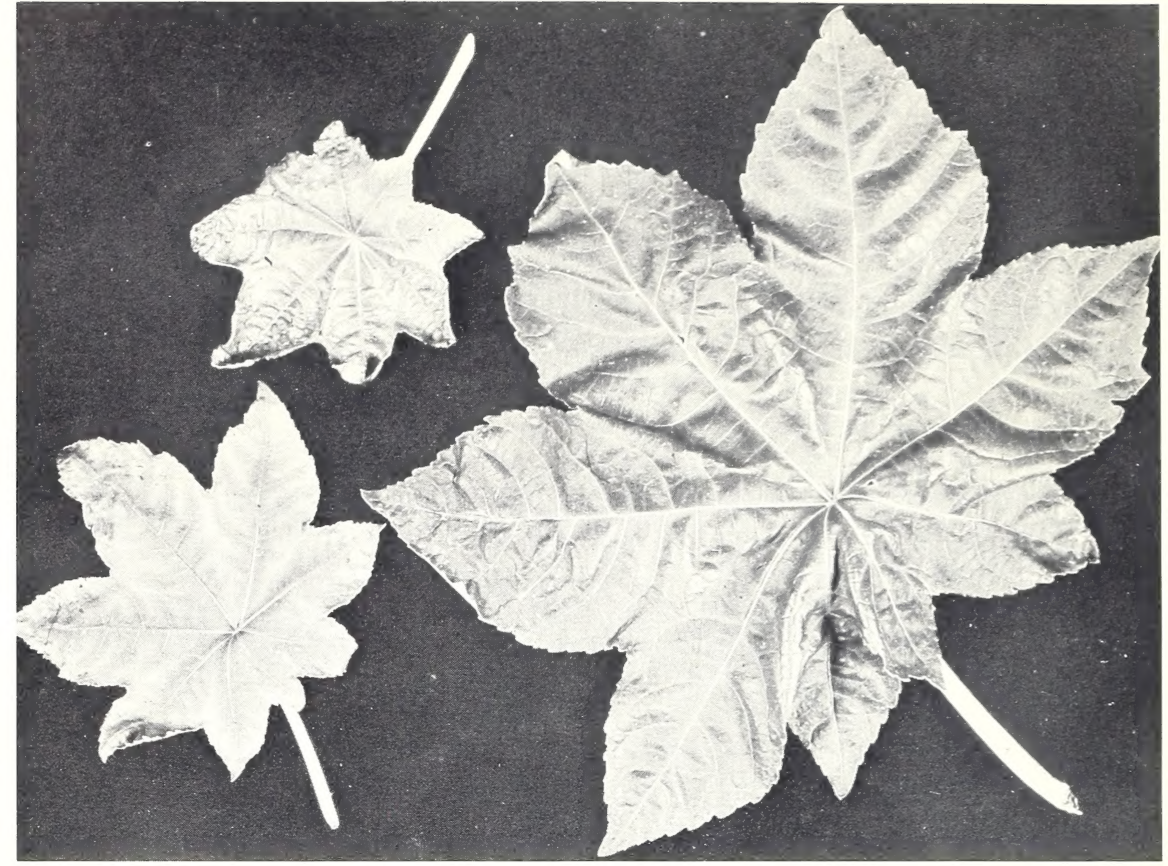

BN-11891

The two castorbean leaves at the left were stunted by zinc deficiency. At right, a normal leaf of the same age.

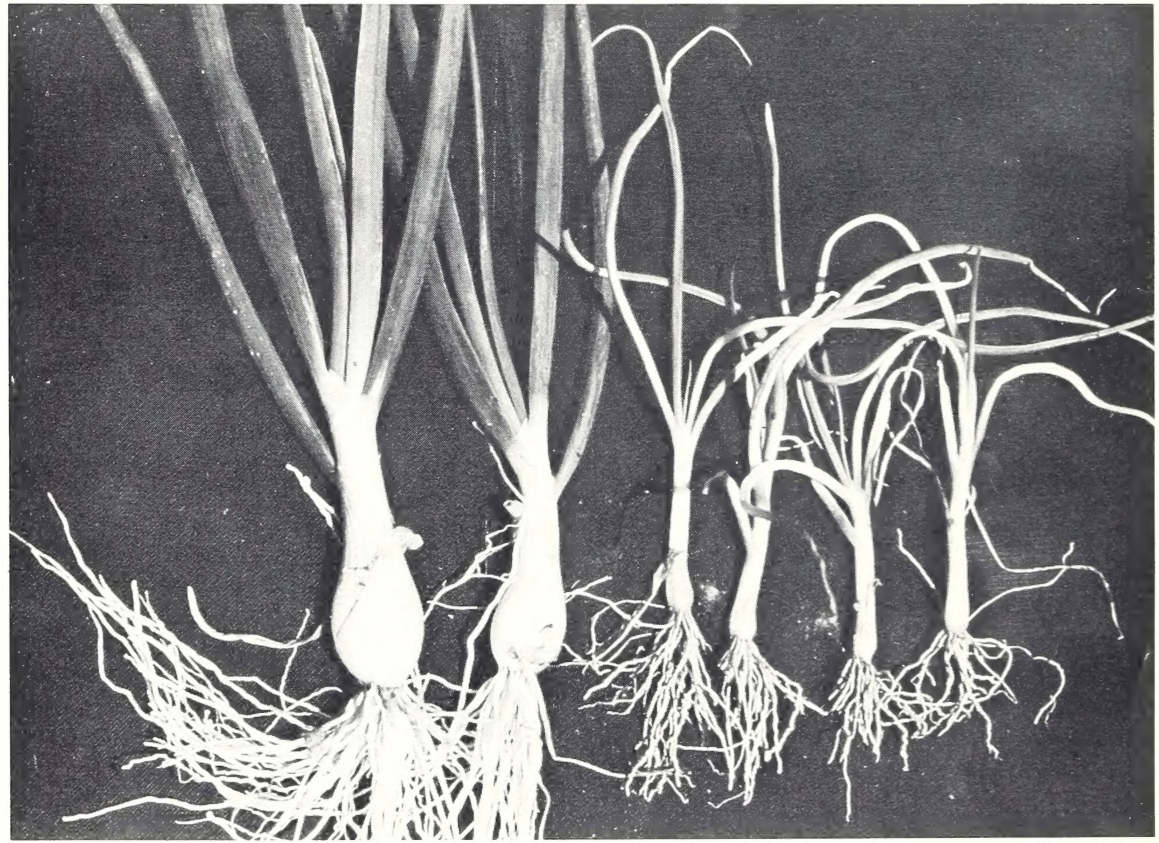

$\mathrm{BN}-11892$

Onions grown on soil that does not provide them with enough zinc are severely stunted and have yellow, crooked tops. At left, normal onions of the same variety and age. 
If you suspect zinc deficiency, the best way to confirm it is to apply a zinc treatment. For a spray test, dissolve a teaspoonful of zinc sulfate in a gallon of water and wet the foliage of several dozen of the abnormal plants with the solution. If zinc-and zinc alone-has been deficient, the treated plants should resume normal growth, and new leaves and stems should show no signs of deficiency.

Spraying is not an effective test method for onions or Russet Burbank potatoes. Where symptoms of zinc deficiency have appeared on either of these crops or have appeared in only mild form on some other crop, zinc treatment for testing purposes may be applied to the soil before the next spring planting. Mix zinc sulfate in the soil at the rate of 2 ounces for each 100 square feet, or apply it at the same rate as a sidedressing at a depth of about 3 inches, 3 inches to the side of the row.

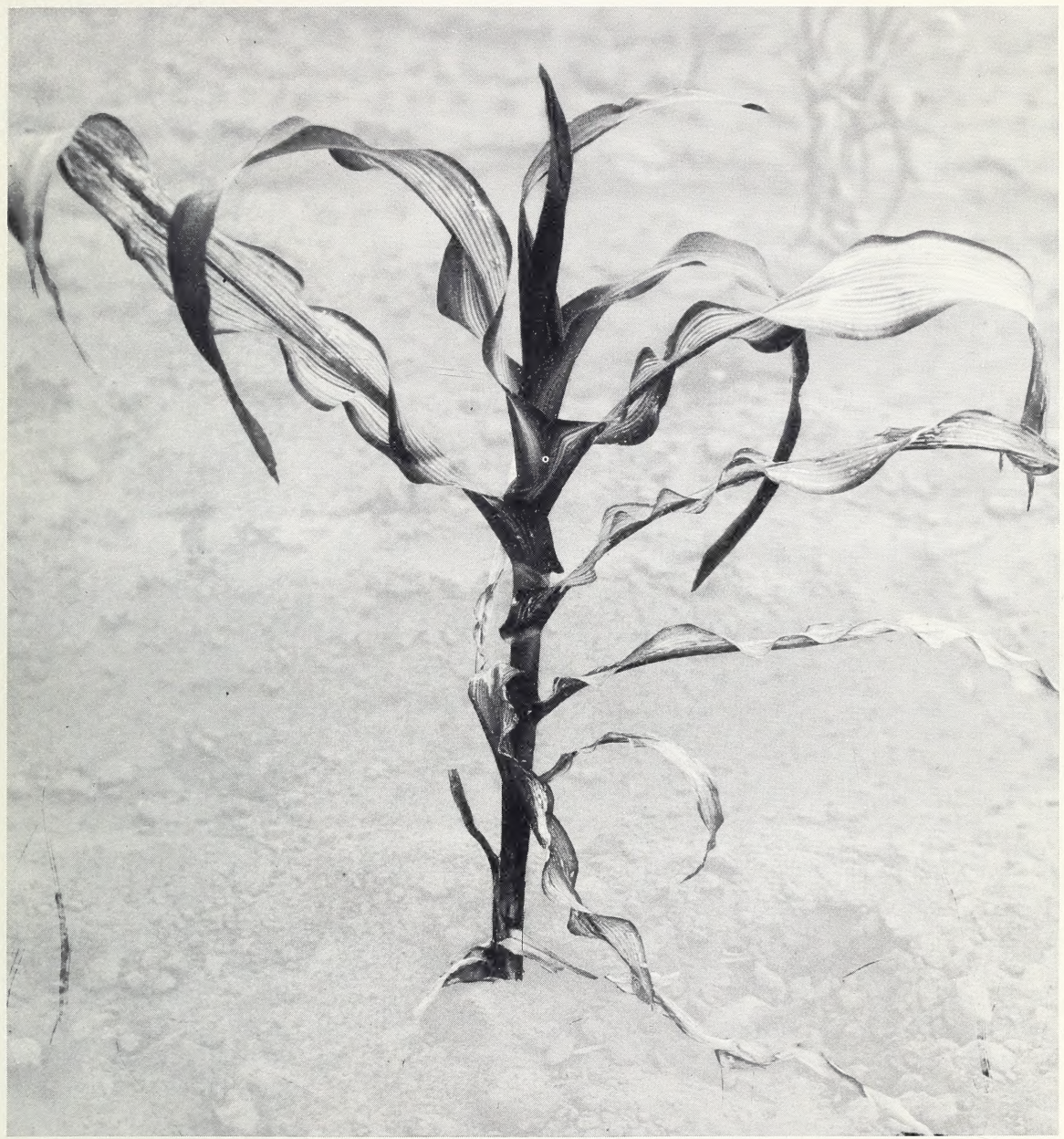

BN-11893

Corn stunted and discolored by zinc deficiency. The earliest symptom on corn is broad bands of light-colored stripes on the lower leaves. Margins, midribs, and tips of the affected leaves stay green. These leaves die prematurely. (Iron deficiency, also, produces striping on corn leaves, but it affects the upper leaves more severely than the lower.) 


\section{How To Correct It}

In an emergency, a foliage spray containing zinc is the best means of correcting zinc deficiency in plants other than onions or Russet Burbank potatoes. To make an effective spray, dissolve 1 pound of zinc sulfate and a cupful of household detergent in 50 gallons of water. Apply the solution when the plants are small, using lowpressure ground spraying equipment. Wet the foliage thoroughly. One or more repeat applications may be neces. sary.

Applying zinc to the soil generally gives better results than spraying it on the foliage, and zinc thus applied is available to plants for 4 or 5 yearsperhaps longer. Any zinc compound that will dissolve in dilute hydrochloric acid is satisfactory as a fertilizer material to be applied to the soil. Such compounds include zinc sulfate, zinc oxide, zinc carbonate, and zinc ammonium sulfite.

(The merits of chelated zincorganic compounds of zinc-as foliage sprays or soil treatments for field or vegetable crops have not offset the higher cost.)

Zinc is held firmly in the soil. It cannot be leached out by rain or by irrigation water. Likewise, it cannot be carried by soil water to the roots of plants. Roots must grow to the zinc. So zinc fertilizer, to serve its purpose, must be mixed into the soil where developing roots can come into contact with it.

For nonsandy soil on which an annual crop is to be seeded, the recommended method of correcting zinc deficiency is to incorporate 10 pounds of zinc per acre into the soil by plowing it under, or drill it in a band 2 inches below the seeding depth, 2 inches to the side of each seed row. On sands, apply 3 to 5 pounds of zinc per acre in the same way. In fields of perennial crops, such as hops, broadcast 20 to 30 pounds of zinc per acre and mix it into the soil, or drill it in a band at a depth of 10 inches, 1 foot to each side of each row of plants.

Any of the zinc compounds recom. mended for use as soil treatments can be applied alone or used in a mixed or liquid fertilizer. Zinc is more effective if banded with nitrogen fertilizer than if banded alone. The zinc content of a commercial mixed fertilizer is printed on the bag. The availability of zinc used in a fertilizer mixture is not reduced by phosphate. If you mix zinc sulfate with dry nitrogen fertilizer, spread the mixture immediately to avoid caking.

Zinc applied to soil or as a foliage spray at the rates recommended. here will not injure crop plants.

\section{How To Prevent It}

Since the surface layer of a soil usually contains most of the available zinc, anything that guards the soil against abnormal erosion helps to prevent zinc deficiency. In addition, the following practices help maintain an adequate supply of available zinc in the soil:

- In using phosphates as fertilizers, take care not to apply them at rates higher than those recommended. For reasons not yet well established, too heavy use of phosphates can cause zinc deficiency in some soils.

- Encourage development of extensive root systems by crop plants. Since zinc cannot move in the soil, its availability to plants depends largely on movement of plant roots to it. Extensive root development is favored by tillage practices that prevent compacting of soil; by methods of water management that prevent waterlogging of soil; and by crop rotations such as those including clover or alfalfa.

Washington, D. C.

Issued November, 1961

For sale by the Superintendent of Documents, U.S. Government Printing Office, Washington 25, D.C. Price 15 cents 